\title{
Application of Regression Models for Area, Production and Productivity Growth Trends of Cotton Crop in India
}

\author{
M. Sundar Rajan*, M. Palanivel \\ Department of Statistics, Govt. Arts College (Affiliated Bharathiar University), Coimbatore, India \\ Email address: \\ sundarraj773@gmail.com (M. S. Rajan) \\ ${ }^{*}$ Corresponding author
}

\section{To cite this article:}

M. Sundar Rajan, M. Palanivel. Application of Regression Models for Area, Production and Productivity Growth Trends of Cotton Crop in India. International Journal of Statistical Distributions and Applications. Vol. 4, No. 1, 2018, pp. 1-5. doi: 10.11648/j.ijsd.20180401.11

Received: September 11, 2017; Accepted: November 11, 2017; Published: January 19, 2018

\begin{abstract}
Computing the growth of any entity over a time period is important for understanding the past behaviour and for future planning. 'Compound growth rate' is one of the frequently used methods for calculating the growth rate models. Among the statistical study was carried out on different growth models viz., linear, quadratic, cubic, exponential, compound, logarithmic, inverse, power, growth and S-curve models to project the area, production and productivity cotton crop in India for 1951 to 2013. The study revealed that through all models exhibited significant; the cubic model is the best fitted, for its highest adjusted $R^{2}$ on increasing future projection trends with respect to area, production and productivity of cotton in India.
\end{abstract}

Keywords: Regression Growth Models, Area, Production, Productivity, Cotton, Adjusted $R^{2}$, Growth Models

\section{Introduction}

Cotton is an important cash crop and India cultivates the highest acreage in the world. It provides the basic raw material (cotton fibre) to the cotton textile industry. Cotton also known as 'White Gold' dominates India's cash crops, and makes up 65 per cent of the raw material requirements of the Indian textile. World cotton production is estimated at 118.95 million bales of $480 \mathrm{lb}$ in 2012-13 (USDA, February, 2013) which is $4 \%$ less than the previous year 2011-12 and cotton area to the tune of $4.62 \%$. India continued to maintain the largest area under cotton and second largest producer of cotton next to china with $34 \%$ of world area and $21 \%$ of world production. Significant drop in the production level in Brazil about $43 \%$ due to $40 \%$ reduction in area under cotton compared to previous year. Though there is reduction of $3.41 \%$ of area under cotton in United States, there is increase of $7.85 \%$ in cotton production compared to $2011-12$. China is going to be the largest importer around 14 million bales of Cotton this year and share of $34 \%$ of the world total cotton imports. Among the major cotton growing countries, Australia tops the productivity level of $2055 \mathrm{~kg} / \mathrm{ha}$ followed by Brazil and Turkey (1415 kg/ha). The major cotton growing states in India are Punjab, Haryana, Rajasthan,
Madhya Pradesh, Gujarat, Maharashtra, Andhra Pradesh, Tamil Nadu and Karnataka.

Growth models can provide a fitting data summary can be valuable for forecasting future movements. Karim et al., (2010), Rimi et al., (2009), Finger, (2007), Chengappa, (1981) etc., used various growth models in different crops. Singh et al., (2014) employed statistical growth analysis in paddy crop by various growth models. Martin and Yeh (1965) and Ahuja (1987) calculated the future projections for the production of various crops. Dhakre and Amod Sharma (2009) had commenced the study to compute the growth rates of Ginger in north-eastern region by using exponential growth model. Aparna et al., (2008) analysed the trend in growth rates of major vegetables in Visakhapatnam district of Andhra Pradesh state with the help of compound growth by using exponential function. Srinivasulu and Srinivasa Rao (2006) analysed growth rates of turmeric and estimated the future projections by using different regression models. Borthakur and Bhattacharya (1998) studied on trend of potato crop in Assam. The Growth model approach is simple to understand and apply for projection of future trends, and is competent of curve fitting a whole range of different models. It also has the advantage that several models, for a given data series, can be simply investigated by highest $R^{2}$ and adjusted $R^{2}$ values thus easing the model selection. In this trend 
investigation studies provide insight to policy makers and researches in policy making. The main objective of this study was to focus on past and future trends of cotton area production and productivity in India by using appropriate forecasting and trend analysis model

\section{Material and Methods}

The present study has been conducted on area, production and productivity of cotton crop in India during the period 1951 to 2013 . The cotton crop secondary data were collected from Cotton Corporation of India (CCI). In his study we have compared different models viz., linear, quadratic, cubic, exponential, compound, logarithmic, inverse, power, S-curve, and growth model for estimating the growth of cotton on area, production, and productivity to find the best fit using the statistical methods such as highest $R^{2}$ and adjusted $R^{2}=\bar{R}^{2}$. Subsequently forecasted the cotton growth using the same statistical methods.

\subsection{Analysis of Techniques}

The goodness of fit is examined by using the co-efficient of determination $\left(R^{2}\right)$. According to Kvalseth (1985) the different models and their $\left(R^{2}\right)$ value are used in model selection as in equation (1). This is most appropriate for nonlinear statistical model.

$$
R^{2}=1-\sum\left(y_{i}-\hat{y}_{i}\right)^{2} \sum\left(y_{i}-\bar{y}\right)^{2}
$$

It would be used as the coefficient of determination for goodness of fit. The potential range of values of this $R^{2}$ is well defined with end points corresponding to perfect fit and complete lack of fit, such as $0<R^{2}<1$, where $R^{2}=1$ corresponds to perfect fit and $R^{2} \geq 0$ for any reasonable model specification. Growth models are that which describe the behaviour of a variable overtime.

\subsection{Forecast Through Regression Models}

Since the variables involved are time and output all possible types of models are used. They models taken under consideration are as follows:

1. Linear Function

The Linear equation is given by $Y_{t}=b_{0}+b_{1} t$

2. Quadratic Function

The Quadratic fit or Second degree is given by $Y_{t}=b_{0}+b_{1} t+b_{2} t^{2}$

3. Cubic Function

Cubic fit or third degree curve is given by $Y_{t}=b_{0}+b_{1} t+b_{2} t+b_{3} t^{3}$

4. Exponential Function

The function of this type can be given by $Y_{t}=a e^{b t}$

5. Compound Function

Compound fit is given by $Y_{t}=a b^{t}$

6. Logarithmic Function

The function of equation is given by $Y_{t}=a+b \operatorname{In}(t)$

\section{Inverse Function}

The mathematical equation is given by $Y_{t}=a+\frac{b}{t}$

8. Power Function

The Fit is given by $Y_{t}=a t^{b}$

9. S-Curve

The fit of equation is given by $Y_{t}=e^{\left(a+\frac{b}{t}\right)}$

10. Growth Function

The mathematical equation is given by $Y_{t}=e^{a+\left(b^{*} t\right)}$

$Y_{t}$ is dependent variable (i. e., area/production/productivity)

$t$ is independent variable, time elements which takes the value $1,2, \ldots \mathrm{n}$ for various years

$a$ is an intercept/ constant

$b$ are regression coefficients.

\subsection{Model Selection}

The choice of the model amongst the available alternatives is judged on adjusted $R^{2}=\bar{R}^{2}$ as the criterion of model selection.

$$
\text { Adjusted }^{2}=\bar{R}^{2}=1-\left[\left(1-R^{2}\right) \frac{n-1}{n-p-1}\right]
$$

Where, $p$ is the number of parameter in the equation and $n$ is the number of observations.

\section{Result and Discussion}

In the above Table 1 shows that descriptive statistics of cotton crop in India. During the area under the cotton crop minimum is $5.88(\mathrm{Lakh} / \mathrm{Hec})$ and maximum is 12.1 $(\mathrm{Lakh} / \mathrm{Hec})$, with the mean of area $8.08(\mathrm{Lakh} / \mathrm{Hec})$ in India. The production of cotton is minimum 3.04 (Lakh bales) and maximum 35.3 (Lakh bales), with mean of production 9.99 (Lakh bales) in India. The productivity (Yield) of cotton is minimum $85(\mathrm{Kg} / \mathrm{Hec})$ and maximum $518(\mathrm{Kg} / \mathrm{Hec})$, with the mean of $198(\mathrm{Kg} / \mathrm{Hec})$ in India.

Table 1. Descriptive statistics of cotton cultivated crop in India.

\begin{tabular}{llll}
\hline Cotton crop & Minimum value & Maximum value & Mean \\
\hline Area & 5.88 & 12.1 & 8.08 \\
Production & 3.04 & 35.3 & 9.99 \\
Productivity & 85 & 518 & 198 \\
\hline
\end{tabular}

The results from Table 2, 3 and 4 revealed that all the values of exactitude measures are highest $R^{2}$ and adjusted $R^{2}$. Based on the analysis, it was found that all the functions were initiate significant. However, the cubic model was selected best fit because of its highest (R-Square) $R^{2}$ for cotton area $(0.77)$, production $(0.91)$ and productivity (0.91). In case of area, the parametric values are 6.345 (a), 0.212 (b), -0.009 (c) and $0.001(\mathrm{~d})$ although in case of production are 0.766 (a), 0.767 (b), -0.033 (c) and 0.001 (d). In case of productivity, the parametric values are 59.645 (a), 7.906 (b), -0.294 (c) and $0.004(d)$.

The best selected goodness of fit statistics reveals that there was marginally difference among the models as far as 
adjusted $R^{2}$ are concerned. The Cubic Function was observed to be the selected best fit for its highest adjusted $R^{2}$ with developed to area, production and productivity (Table 2, 3 and 4). Hence, the future projections of area, production and productivity of cotton crop in India were calculated based on the cubic model and are presented in Table 5.

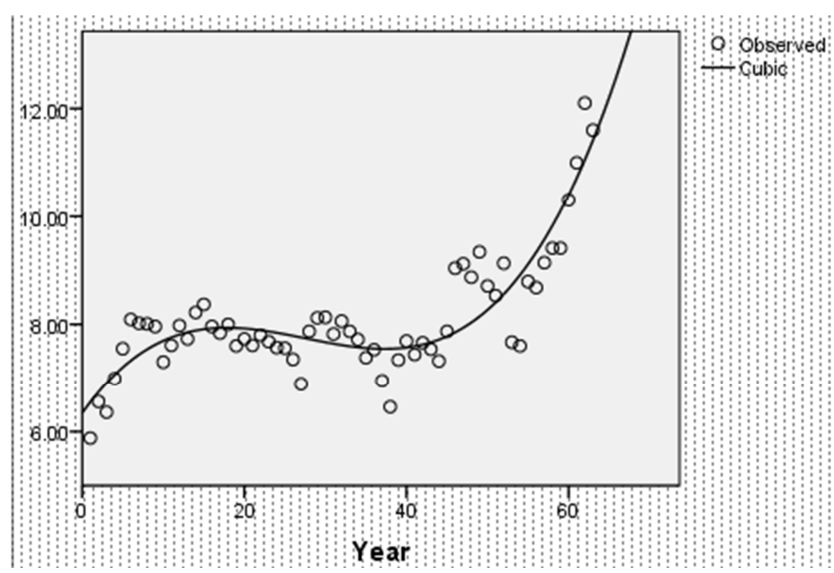

Figure 1. Area of Cotton crop in India.

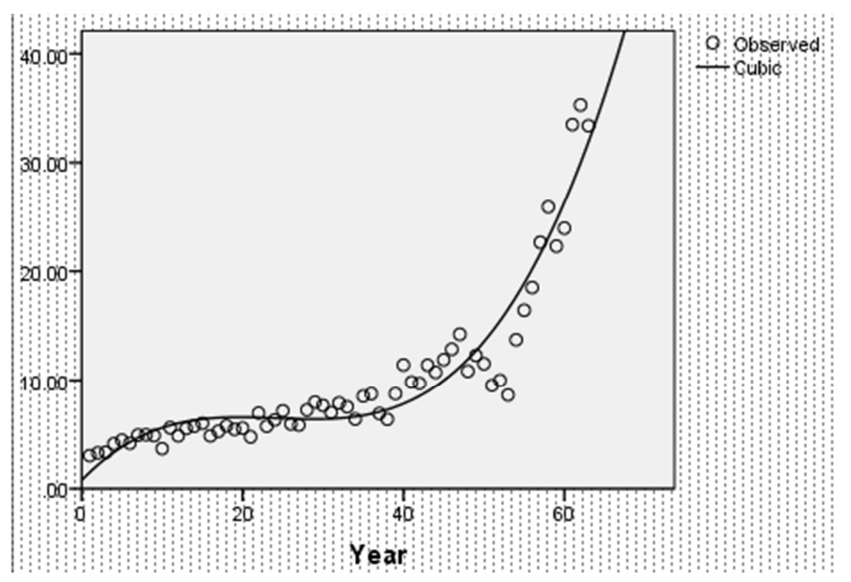

Figure 2. Production of Cotton in India.

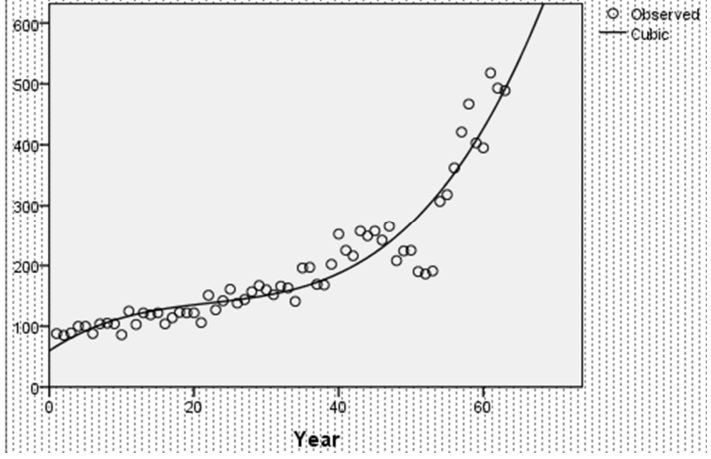

Figure 3. Productivity of Cotton in India.

Obviously, accurate growth models should be computed by identifying the model which describes agreeably the path followed by response variable over time. Time series growth modelling can be applied to forecast the future cotton crop area, production and productivity, as there is limited studies in cotton projection. Statistical modelling will be of immense help in formulating suitable strategies and planning for law makers in future cotton crop development.

All the iterative procedures require starting values of the parameters. The select of good initial values can spell the difference between success and failure in locating the fitted value or between rapid and slow convergence to the solution. It has been observed from Tables 2, 3 and 4 that all the ten models have been fitted well with the dataset. However, when we compared the models based on various Goodness of fit criteria it was found that cubic model performed better than the other models. The cubic model was found to be the best fit for its highest adj $R^{2}$ for sugarcane crop in Andhra Pradesh, Mohan Naidu [10].

Hence, the results revealed that the cotton area, production and productivity in India by 2020 were calculated. The projection values were 15.17 (lakh/ha), 51.72 (lakh/bales) and $715(\mathrm{Kg} / \mathrm{ha})$ as per the best fit cubic function. The projections of cotton statistics were area, production and productivity showed an increasing trend (Table 2, 3 and 4), which means that area, production and productivity of cotton in India will increase when compared with earlier trend 1951-2013 (Table 5).

Table 2. Parametric values in regression equations of Cotton Area in India.

\begin{tabular}{lllllllllll}
\hline & Linear & Logarithmic & Inverse & Quadratic & Cubic & Compound & Power & S & Growth & Exponential \\
\hline A & 6.823 & 5.900 & 8.331 & 7.808 & 6.345 & 6.922 & 6.135 & 2.114 & 1.935 & 6.922 \\
B & 0.039 & 0.685 & -3.262 & -0.051 & 0.212 & 1.005 & 0.084 & -0.432 & 0.005 & 0.005 \\
C & & & & 0.001 & -0.009 & & & & & \\
D & & & & & 0.001 & & & & \\
R Square & 0.421 & 0.308 & 0.176 & 0.566 & 0.772 & 0.424 & 0.344 & 0.231 & 0.424 & 0.424 \\
Adjusted R Square & 0.412 & 0.297 & 0.162 & 0.551 & 0.760 & 0.415 & 0.333 & 0.217 & 0.415 & 0.415 \\
\hline
\end{tabular}

Table 3. Parametric values in regression equations of Cotton Production in India

\begin{tabular}{|c|c|c|c|c|c|c|c|c|c|c|}
\hline & Linear & Logarithmic & Inverse & Quadratic & Cubic & Compound & Power & $\mathbf{S}$ & Growth & Exponential \\
\hline $\mathrm{A}$ & -0.393 & -6.145 & 11.226 & 6.994 & 0.766 & 3.175 & 1.546 & 2.26 & 1.155 & 3.175 \\
\hline B & 0.325 & 5.058 & -16.416 & -0.357 & 0.767 & 1.030 & 0.524 & -2.023 & 0.030 & 0.030 \\
\hline $\mathrm{C}$ & & & & 0.011 & -0.033 & & & & & \\
\hline $\mathrm{D}$ & & & & & 0.001 & & & & & \\
\hline R Square & 0.642 & 0.379 & 0.100 & 0.825 & 0.909 & 0.862 & 0.649 & 0.243 & 0.862 & 0.862 \\
\hline Adjusted R Square & 0.636 & 0.369 & 0.086 & 0.819 & 0.905 & 0.860 & 0.643 & 0.231 & 0.860 & 0.860 \\
\hline
\end{tabular}


Table 4. Parametric values in regression equations of Cotton Productivity in India.

\begin{tabular}{lllllllllll}
\hline & Linear & Logarithmic & Inverse & Quadratic & Cubic & Compound & Power & S & Growth & Exponential \\
\hline A & 30.816 & -69.963 & 218.842 & 120.166 & 59.645 & 77.944 & 42.795 & 5.282 & 4.356 & 77.944 \\
B & 5.233 & 84.074 & -273.893 & -3.014 & 7.906 & 1.026 & 0.441 & -1.592 & 0.025 & 0.025 \\
C & & & & 0.129 & -0.294 & & & & \\
D & & & & 0.004 & & & & \\
R Square & 0.747 & 0.468 & 0.125 & 0.866 & 0.902 & 0.890 & 0.661 & 0.217 & 0.890 & 0.890 \\
Adjusted R Square & 0.742 & 0.460 & 0.111 & 0.862 & 0.897 & 0.888 & 0.656 & 0.204 & 0.888 & 0.888 \\
\hline
\end{tabular}

Table 5. Projection of area, production and productivity of cotton in India.

\begin{tabular}{|c|c|c|c|c|c|c|c|c|c|}
\hline \multicolumn{4}{|c|}{ Area (lakh. ha) } & \multicolumn{3}{|c|}{ Production (lakh. bales) } & \multicolumn{3}{|c|}{ Productivity (Kg/ha) } \\
\hline Year & Forecast & LCL & UCL & Forecast & LCL & UCL & Forecast & LCL & UCL \\
\hline 2013 & 11.80 & 10.56 & 13.04 & 34.00 & 28.80 & 39.20 & 516 & 435 & 597 \\
\hline 2014 & 12.20 & 10.93 & 13.48 & 36.18 & 30.83 & 41.53 & 541 & 457 & 624 \\
\hline 2015 & 12.63 & 11.32 & 13.95 & 38.48 & 32.95 & 44.01 & 567 & 481 & 653 \\
\hline 2016 & 13.09 & 11.72 & 14.46 & 40.89 & 35.15 & 46.63 & 594 & 505 & 683 \\
\hline 2017 & 13.57 & 12.14 & 14.99 & 43.41 & 37.43 & 49.39 & 622 & 529 & 715 \\
\hline 2018 & 14.07 & 12.58 & 15.57 & 46.06 & 39.80 & 52.32 & 652 & 555 & 749 \\
\hline 2019 & 14.61 & 13.04 & 16.17 & 48.83 & 42.26 & 55.40 & 683 & 581 & 785 \\
\hline 2020 & 15.17 & 13.52 & 16.81 & 51.72 & 44.80 & 58.64 & 715 & 607 & 823 \\
\hline
\end{tabular}

\section{Conclusion}

The present study regression parameter for estimating of cultivated cotton crop area, production and productivity in India. Appropriateness of a model was judged by the magnitude and sign of the parameter estimates and goodness of fit viz., adjusted $R^{2}$ for best fit model. The developed regression model for cotton was found to be best fitted in cubic regression model and cotton crop area, production and productivity of India during the study period increased trends (Table 5). With a view to making a final choice about the best model, there is need to study some additional features of this cubic model only when this is done, we shall be able to make a final decision about the best model.

Finally, the selected model for cotton area, production and productivity was used eight years forecast. The forecast are shown in Table 5 at 95\% confidence interval. Form Table 5, the area of the forecast for the years 2013 was 11.80 (lakh/ha) with a $95 \%$ confidence limit of $(13.04,10.56)$ lakhs hectare. And the production for the forecast the same the year was 34.00 (lakh/bales) with a $95 \%$ confidence limit of $(39.20,28.80)$ lakh bales. Finally, then productivity for the year 2013 was $516(\mathrm{~kg} / \mathrm{hec}$.) with $95 \%$ confidence limit of $(597,435)$ Kilogram per hectare. It was found that is cotton crop well improved, then the cotton area, production and productivity in the year 2020 would be 15.17 (lakh/ha), 51.72 (lakh/bales) and $715(\mathrm{~kg} / \mathrm{hec}$ ) with a $95 \%$ confidence limit of area $(16.81,13.52)$ lakhs hectare, production $(58.64,44.80)$ lakhs bales and productivity $(823,607)$ kilogram per hectare.

This analysis provides the most valuable insight for the specific strain that was used. Although data a specific to strain, area, production and productivity conditions, or particular environments will improve the value of the model in commercial applications, this paper provides an integrated generalized nonlinear model that can be applied to a wide range of supply chain optimization problems.

\section{References}

[1] Aparna, B., S. M. Shareef, V. T. Raju and V. Srinivasa Rao (2008). Growth trends of major vegetables in Visakhapatnam. The Andhra Agricultural Journal, 55 (1), 68-69.

[2] Ahuja, K. N., 1987. Indian's food demand in 2000. International Seminar on Agricultural Research Systems and Management in the $21^{\text {st }}$ Century. NARM, Hyderabad, December 8-10, ppA32-41.

[3] Borthakur. S and B. K. Bhattacharyya (1998). Trend analysis of Area, Production and Productivity of Potato in Assam 1951-1993, Economic Affairs. Vol. 43 (4) issue.

[4] Chengappa, P. G., 1981, Growth rates of area, production and productivity of coffee, Indian Journal of Coffee Research. 11 (2): 19-26.

[5] Dhakre and Amod Sharma (2009). Growth and instability analysis of ginger production in North-east: region. Agricultural Situation in India. 463-465.

[6] D. P. Sing et al., (2014). Developing statistical models to study the growth rates of paddy crops in different districts of Chhattisgarh, American International Journal of Research in Formal, Applied \& Natural Science. 5 (1), 102-104.

[7] Finger, R., (2007). Evidence of slowing yield growth the example of swiss cereal yield. Agri-Food and AgriEnvironmental Economics Group, ETH Zurich, Switzerland.

[8] Hussaini. Mairiga, (2014). Trend Analysis of Productivity of Some Selected Cereal Crops in Nigeria: 1983-2008. Tahir, Research on Humanities and Social Sciences. Vol. 4, No. 8, 2014.

[9] Karim, M. R., M. A. Awal and M. Akter, (2010). Forecasting of wheat production in Bangladesh. Bangladesh J. Agric. Res., 35: $17-28$.

[10] Kvalseth, T. O. (1985). Cautionary note about $\left(R^{2}\right)$, Amer. Statistician, 39, 279-85. 
[11] Martin and Yeh, H. 1965. Yield predictions for 1965 wheat, oats and barely in Manitoba. Canadian Journal of Agricultural Economic. 13: 306-309.

[12] Mohan Naidu. G., (2015). Selection of appropriate growth model for projection of sugarcane area, production and productivity of Andhra Pradesh. International Journal Agricultural Statistical Science. Vol. 11, No. 1, pp. 215-218.

[13] Rajarathinam, A., Parmar, R. S. and Vaishnav P. R. 2010. Estimating Models for Area, Production and Productivity
Trends of Tobacco (Nicotiana tabacum) Crop for Anand Region of Gujarat State, India. J. App. Sci., 10: 2419-25.

[14] Rimi, R. H., S. H. Rahman, S. Karmakar and S. G. Hussain, (2009). Trend analysis of climate change and investigation on its probable impacts on rice production at Sathkhira, Bangladesh. Pak. J. Meteorol., 6: 37-50.

[15] Srinivasa Rao, V and Srinivasulu, R. (2006). Growth comparisons of turmeric up to 2020 AD. The Andhra Agricultural Journal. 53 (1\&2): 108-109. 